\title{
Biossimilares:
}

\section{Velhas Questões, Novos Desafios}

\section{Biosimilars: Old Issues, New Challenges}

Rita Oliveira ${ }^{1}$, Teresa Aires ${ }^{2}$

\section{RESUMO}

De acordo com a Agência Europeia de Medicamentos, EMA, um biossimilar é aquele que é obtido pela biotecnologia contendo uma versão da substância ativa da medicina biológica original previamente autorizada no Espaço Económico Europeu.

A semelhança entre o medicamento de referência e biossimilar em termos de qualidade, atividade biológica, segurança e eficácia deve ser estabelecida de acordo com critérios de comparabilidade abrangentes.

PALAVRAS-CHAVE: Aprovação de Medicamentos; Biológicos; Biossimilares; Equivalência Terapêutica; Europa; Vigilância de Produtos Comercializados

\section{ABSTRACT}

According to the European Medicines Agency, EMA, a biosimilar is one that is obtained by biotechnology containing a version of the active substance of the original biological medicine previously authorized in the European Economic Area.

The similarity between the reference and biosimilar drug in terms of quality, biological activity, safety and efficacy must be established in accordance to comparability criteria.

KEYWORDS: Biological Products; Biosimilar Pharmaceuticals; Drug Approval; Europe; Product Surveillance Postmarketing; Equivalency 


\section{INTRODUÇÃO}

Os avanços tecnológicos das últimas décadas possibilitaram o aparecimento de um novo ramo da Ciência - a Biotecnologia, que transformou e revolucionou a investigação científica.

Métodos engenhosos de isolamento, análise e manipulação do ADN permitiram avanços no conhecimento dos processos biológicos de inúmeras doenças humanas e metodologias terapêuticas, que permitiram à indústria farmacêutica modelar e sintetizar moléculas cada vez mais eficazes e seguras.

Os medicamentos biológicos revolucionaram a medicina e representam atualmente a maior fonte de inovação da indústria farmacêutica, vindo dar resposta a inúmeras doenças até então não tratadas de forma eficaz com as terapias tradicionais como o cancro, doenças autoimunes, etc. ${ }^{1}$

\section{O QUE SÃO MEDICAMENTOS BIOLÓGICOS?}

Nos últimos 30 anos, a química orgânica cedeu o lugar à biotecnologia molecular e abriu novos horizontes com inovações surpreendentes como a insulina humana recombinante, às quais se seguiram a hormona de crescimento, as heparinas, os interferões, as interleucinas, os fatores de crescimento, os trombolíticos, os anticorpos monoclonais, as proteínas de fusão, etc.

Os medicamentos biológicos ou biofármacos são produzidos por mecanismos de biossíntese em células vivas, dando origem a proteínas, moléculas de grandes dimensões, compostas por milhares de átomos, instáveis e de elevada complexidade.

Ao contrário dos medicamentos de origem sintética, que podem ser produzidos com um elevado grau de pureza e que são facilmente replicados, o princípio ativo do medicamento biológico é constituído por uma mistura de subespécies moleculares, cujo produto final é fortemente dependente do processo de produção e da variabilidade dos produtos utilizados, que conferem ao produto final um elevado grau de micro-heterogeneidade entre os diferentes lotes produzidos. ${ }^{1-3}$

O processo de produção consiste na seleção e clonagem de um gene num vetor que é transferido para uma célula hospedeira, ocorrendo, posteriormente, os processos de cultura celular, fermentação, purificação e, finalmente, a formulação e ampliação de escala. Será deste modo expectável que diferentes processos de fabrico originem produtos com ligeiras diferenças e que, mesmo entre diferentes lotes do mesmo produto se verifique, como já foi referido, uma certa micro-heterogeneidade. ${ }^{4}$
Adicionalmente, estes medicamentos sofrem diversas alterações no seu processo de produção, ao longo do seu ciclo de vida, em resultado da inovação tecnológica.

Assim, quando ocorre a quebra de patente dos medicamentos originais, as cópias legais dos produtos obtidos por síntese química, os medicamentos genéricos, são idênticos ao original e por consequência equivalentes. Ao passo que as cópias autorizadas dos medicamentos biológicos, em princípio diferentes, são usualmente chamadas de biossimilares, necessitando essa biossimilaridade de ser sempre comprovada por um conjunto de estudos comparativos. ${ }^{4}$

TABELA 1. Diferenças entre medicamentos de origem química e os de origem biológica.

\begin{tabular}{|c|c|c|}
\hline Medicamentos & Origem Sintética & Origem Biológica \\
\hline Moléculas & Pequenas & Grandes \\
\hline Estrutura & Simples & Complexa \\
\hline Estabilidade & Estáveis & Instáveis \\
\hline Caracterização & $\begin{array}{l}\text { Simples e } \\
\text { completa }\end{array}$ & $\begin{array}{l}\text { Difícil e } \\
\text { incompleta }\end{array}$ \\
\hline Produção & $\begin{array}{l}\text { Processo químico } \\
\text { previsível } \\
\text { Possibilidade } \\
\text { cópias idênticas }\end{array}$ & $\begin{array}{l}\text { Variável, } \\
\text { produzido por } \\
\text { sistemas vivos } \\
\text { Impossibilidade } \\
\text { cópias idênticas }\end{array}$ \\
\hline Patentes & Geralmente única & Múltiplas \\
\hline Imunogenicidade & Ocasional & Frequente \\
\hline
\end{tabular}

\section{BIOSSIMILARIDADE}

"Biossimilaridade" é o termo regulamentar utilizado pela União Europeia (UE) para se referir à comparabilidade entre um biossimilar e o seu medicamento de referência.

O conceito de biológico similar ou simplesmente biossimilar, foi introduzido pela primeira vez na legislação europeia há cerca de 10 anos através da "Commission Directive 2003/63/EC, Directive 2004/27/EC". 5,6

A Agência Europeia do Medicamento (EMA) define biossimilar como um produto que é similar a um medicamento biológico já autorizado, chamado medicamento de referência.

A Comissão Europeia aprovou o primeiro medicamento biossimilar há 10 anos e desde então aprovou já 19 especialidades de 7 moléculas diferentes (somatropina, epoietina alfa, epoietina zeta, filgrastim, infliximab, folitropina alfa e insulina glargina). ${ }^{6}$

A autorização de introdução no mercado de um medicamento biossimilar é baseada numa avaliação regulamentar, em que o requerente demonstrou a existência de similaridade entre o seu produto e o medicamento 
de referência através dos métodos estabelecidos nas "orientações científicas sobre medicamentos biossimilares" específicas do Comité de Medicamentos de Uso Humano (CHMP) /EMA. ${ }^{7,8}$

Os medicamentos biossimilares são sistematicamente desenvolvidos para serem altamente similares ao medicamento de referência relativamente à qualidade, segurança e eficácia.

O desenvolvimento do medicamento biossimilar inicia-se com a definição das características moleculares e dos atributos de qualidade em relação ao perfil do medicamento biossimilar alvo e a sua comparabilidade com o medicamento de referência.

O exercício de comparabilidade realiza-se em três etapas distintas que incluem comparabilidade da qualidade, físico-química e biológica, comparabilidade não-clínica, estudos não-clínicos comparativos e comparabilidade clínica, através de estudos clínicos comparativos.,78

A comparabilidade da qualidade é estabelecida relativamente à estrutura molecular, assim como, relativamente à funcionalidade e deve ser demonstrada mediante uma caracterização analítica detalhada. Para tal realizam-se relevantes de ligação ao recetor e bioensaios, estes últimos realizados com o medicamento biossimilar e o medicamento de referência através de um método comparativo rigoroso.

Os medicamentos biológicos são frequentemente utilizados em mais do que uma indicação terapêutica. É possível a extrapolação dos dados clínicos de eficácia e de segurança a outras indicações do medicamento de referência que não tenham sido especificamente estudadas durante o desenvolvimento clínico do biossimilar, tendo por base a evidência global obtida sobre a comparabilidade e com uma justificação científica adequada. Este inclui, pelo menos, um estudo clínico na população de doentes mais sensíveis com monitorização dos parâmetros clínicos. Sempre que a evidência central de comparabilidade se basear em aspetos farmacodinâmicos, e se para as indicações reivindicadas se aplicarem diferentes mecanismos de ação (ou em caso de incerteza), então os requerentes devem apresentar dados relevantes para justificar a extrapolação a todas as indicações clínicas. ${ }^{9,10}$

Só quando a qualidade e a comparabilidade não-clínica e clínica forem alcançadas, é que o novo medicamento é aceite como um medicamento biossimilar e se considera como justificado que o medicamento biossimilar faça referência aos dados clínicos obtidos a partir da vasta experiência adquirida com o medicamento de referência.

A decisão se a extrapolação de múltiplas indicações é aceitável (ou não) é determinada caso a caso pelo CHMP/EMA.

\section{SWITCH TERAPÊUTICO}

Uma vez introduzido no mercado, o biossimilar converte-se numa alternativa terapêtica dentro do mesmo grupo terapêutico do medicamento de referência, tendo a EMA deixado o tema da "intermutabilidade" e/ou "substituição" para decisão de cada estado membro, que no caso de Portugal é o INFARMED.

Alguns aspetos da regulamentação dos biossimilares estão ainda indefinidos, controversos ou são específicos de cada país. Um deles é a questão do switch terapêutico ou substituição automática.11,12

A Comissão Nacional de Farmácia e Terapêutica (CNFT), enquanto órgão consultivo do INFARMED, I.P., considera que a disponibilidade e a utilização crescente de medicamentos biossimilares melhoram a competição entre produtos, com o potencial de melhorar o acesso dos doentes a medicamentos biológicos e contribuir para a sustentabilidade dos sistemas de saúde.

A CNFT refere que decisão de tratar um doente com um medicamento biossimilar, ou com o seu biológico de referência, deverá ser tomada na sequência do parecer de um profissional de saúde qualificado, de acordo com as seguintes orientações:

- Na seleção entre alternativas terapêuticas envolvendo medicamentos biológicos é recomendado optar, sempre que possível, por substâncias ativas que disponham de biossimilares;

- Para os doentes que vão iniciar o tratamento, a CNFT recomenda que, nos casos em que exista biossimilar, seja disponibilizado aos doentes o medicamento biológico mais acessível, em todas as indicações para as quais ele estiver aprovado;

- Em termos de farmacovigilância é muito importante a rastreabilidade do medicamento biológico envolvido na reação adversa potencial, pelo que deve ser mantida a mesma marca de medicamento durante o tempo expectável à ocorrência dessa mesma reação;

- A mudança entre medicamentos biológicos biossimilares deve respeitar um período mínimo de tempo que salvaguarde a sua rastreabilidade. Este período pode ser definido no Formulário Nacional do Medicamento (FNM) para diferentes medicamentos, sendo que quando omisso, não deverá ser inferior a 6 meses;

- A mudança entre marcas diferentes do mesmo medicamento biológico deve ser articulada com os servi- 
ços clínicos envolvidos, com respeito pelo princípio da precaução e de acordo com as indicações terapêuticas para cada situação. Esta posição é revista sempre que estiver disponível evidência científica aplicável.12,13

\section{INDICAÇÕES TERAPÊUTICAS}

Os primeiros medicamentos biossimilares são cópias de proteínas humanas endógenas: eritropoietina, insulina, hormona do crescimento e citocinas. Estes medicamentos revolucionaram o tratamento de muitas doenças, incluindo a anemia, a diabetes, o cancro, a hepatite, a esclerose múltipla, artrite reumatoide, psoríase, lúpus eritematoso sistémico e doença de Crohn.

No tratamento de doenças inflamatórias, mesmo as de etiologia autoimune, os medicamentos biológicos atuam bloqueando importantes mediadores endógenos da inflamação, gerando ação analgésica e anti-inflamatória limitando o dano gerado pela cronicidade.,

Os agentes biológicos e biossimilares podem ser: hormonas (hormona do crescimento, hormona da paratiroide, insulina); interferões (proteínas de resposta a uma infeção viral ou outro estímulo); interleucinas (citocinas); anticorpos monoclonais (MAbs); anticorpos policlonais (PAbs); polipéptidos; proteínas e vacinas (antigénios derivados de um organismo portador da doença e que provoca a produção de anticorpos específicos para esses antigénios, conferindo imunidade/proteção ativa através da indução da imunidade ativa e da memória imunológica).

\section{"The process is the product" - Cada produto biofarmacêutico é único}

Durante o processo de produção, vários fatores podem originar variações nos medicamentos biológicos, alterando o seu perfil de segurança e a eficácia: seleção da linha celular; características biofísicas das proteínas; alterações na temperatura ou nas condições de pH durante as fases de fabrico; manuseamento e conservação do produto nas várias etapas; formulação do produto farmacológico; escala de produção e local de produção.

Tal como foi referido anteriormente, o desenvolvimento e fabrico de medicamentos que contêm proteínas recombinantes incluem fases que vão desde a clonagem de sequências de ADN para um vetor; a transferência desse vetor para a célula hospedeira e todos os outros processos que a transformam num banco de células (crescimento das células recombinantes, purificação da proteína alvo e incorporação numa formulação e dispositivo de transporte, armazenamento e aplicação aos doentes).
Todo este processo decorre sob ambiente estritamente controlado, com condições validadas e sistemas fechados que assegurem a consistência e evitem qualquer contaminação. Desta forma, proteínas produzidas por processos diferentes não possuem propriedades idênticas, sendo improvável que a substância ativa entre dois produtos seja idêntica. ${ }^{4,8}$

\section{IMUNOGENICIDADE E SEGURANÇA}

Imunogenicidade consiste na propriedade inerente a uma molécula de estimular uma resposta imunológica.

Os produtos fabricados pela biotecnologia induzem uma resposta imunitária complexa que consiste na indução da formação de anticorpos "neutralizantes", ativação das células T ou ativação da resposta imunológica inata. Estes fenómenos podem contribuir para que surjam respostas potencialmente adversas: perda da eficácia, anafilaxia e para proteínas terapêuticas usadas como substituição, um potencial de reatividade cruzada com o homólogo endógeno. ${ }^{14,15}$

Vários fatores podem influenciar a imunogenicidade das proteínas terapêuticas, podendo estar relacionados com o doente, a doença ou o produto.

Existem várias condições que predispõem o indivíduo a uma reposta imune, nomeadamente a presença de doença subjacente, a base genética, o estado imunológico, incluindo terapia imunomoduladora e o próprio esquema de administração.

Fatores relacionados com o produto biotecnológico também influenciam o aparecimento de resposta imune, por exemplo, os processos de produção, a formulação, a fonte dos excipientes e características de estabilidade.

A via de administração e a dose podem potenciar a resposta imunológica a uma proteína terapêutica. Medicamentos administrados por via intravenosa são habitualmente menos imunogénicos que os administrados pela via subcutânea ou intramuscular. ${ }^{15}$

Em tratamentos a curto prazo é menos frequente a associação de resposta imune quando comparados com tratamentos a longo prazo, e medicamentos administrados continuamente são geralmente menos imunogénicos que quando administrados intermitentemente.

A perda da eficácia e alteração no perfil de segurança não estão necessariamente correlacionados, podendo ocorrer questões de segurança sem que haja perda do efeito terapêutico. ${ }^{11,12,15}$ 


\section{FARMACOVIGILÂNCIA E PLANO DE GESTÃO DE RISCO (RMP)}

Ao fabricante do medicamento biológico, é exigido, juntamente com o pedido de autorização de comercialização, um plano de gestão de risco, de acordo com a legislação em vigor na União Europeia e de acordo com as guidelines de farmacovigilância incluindo a "CHMP Guideline on Risk Management Systems for Medicinal Products for Human Use (EMA/CHMP/96268/2005)".

A informação relacionada com a imunogenicidade deve constar do plano de gestão de risco (RMP), tendo em conta os eventos detetados e identificados durante o desenvolvimento do produto, assim como, os potenciais riscos e consequências de respostas imunes indesejadas nos doentes. ${ }^{14,15}$

O plano de gestão de risco deve incluir: a identificação e caracterização do risco; plano de monitorização do risco; estratégias e atividades para minimização do risco e como comunicar o risco, no período pré e pós-comercialização.

Os medicamentos biológicos, como uma vacina ou um medicamento derivado do plasma (sangue), para o qual existe pouca experiência na fase pós-comercialização, estão sujeitos a um regime de monitorização adicional pelas entidades competentes, INFARMED / Comité de Avaliação do Risco em Farmacovigilância (PRAC) da Agência Europeia de Medicamentos.

Estes medicamentos apresentam um triângulo preto invertido no Folheto Informativo e no Resumo das Características do Medicamento (RCM), juntamente com uma frase curta que explica o significado do triângulo: "Este medicamento está sujeito a monitorização adicional". Os doentes e os profissionais de saúde devem notificar quaisquer suspeitas de efeitos secundários observados com estes medicamentos para que possam ser analisadas de forma mais eficiente.

O plano de gestão de risco associado ao uso de biossimilares exige estreita cooperação entre os principais intervenientes no domínio da farmacovigilância. Este compromisso de colaboração é vital para que os futuros desafios em matéria de farmacovigilância sejam cumpridos.

Compreender e abordar em conjunto a farmacovigilância destes medicamentos é uma condição essencial para desenvolvimento e futuro dos biossimilares. ${ }^{14-16}$

\section{CONCLUSÃO}

A abordagem padrão para um medicamento genérico (bioequivalência para estudos de biodisponibilidade) é aplicável a medicamentos de síntese química e não é suficiente para produtos resultantes da biotecnologia, devido à sua complexidade estrutural.

A permutabilidade e substituição no ato da prescrição e dispensa é um aspeto que deve ser tratado por cada Estado-Membro da União Europeia, conforme relatado pela Agência Europeia do Medicamento. Deverá existir uma rigorosa farmacovigilância e rastreabilidade para que seja possível avaliar o sucesso terapêutico e possíveis reações adversas relacionadas com a imunogenicidade.

Os profissionais de saúde e o público devem ser informados de forma consistente em todos os Estados-Membros sobre questões de segurança relevantes para cada biossimilar autorizado.

O conceito de medicina biológica semelhante (biossimilar) foi introduzido pela primeira vez na legislação europeia há mais de 10 anos e a EMA é pioneira na regulamentação dos biossimilares.

De acordo com a legislação europeia, todos os medicamentos que provêm de processos de biotecnologia (incluindo biossimilares) são avaliados de forma centralizada pela EMA e aplicáveis a todos os Estados-Membros. As decisões sobre permutabilidade e/ou substituição estão fora do âmbito da EMA e contam com as autoridades competentes de cada país. ${ }^{17}$

Os medos relativos ao uso de biossimilares por diferenças em questões de eficácia e de segurança não são novos e em parte são devidos à falta de informação dos profissionais de saúde e do público em geral, contudo, a alteração de um biológico por outro já é uma prática clínica corrente, por exemplo a alteração da eritropoietina para darbepoetina ou a mudança de filgrastim para pegfilgrastim.

Em qualquer caso, como de costume, o princípio da prudência, determinado pela avaliação da razão benefício/ risco e assente num bom plano de comunicação em saúde que inclua os profissionais e doentes, deverá cimentar a penetração de biossimilares na prática clínica.

CONFLITOS DE INTERESSE: Os autores declaram a inexistência de conflitos de interesse na realização do presente trabalho.

FONTES DE FINANCIAMENTO: Não existem fontes externas de financiamento para a realização deste artigo.

\section{REFERÊNCIAS}

1. Revers L, Furczon E. An introduction to biologics and biosimilars. Part I: Biologics: what are they and where do they come from? Can Pharm J. 2010;143:134-9.

2. McCamish M, Woollett G. The state of the art in the development of biosimilars. Clin Pharmacol Ther. 2012;91:405-17. 
3. Alerany C, Armellini A, Bosó V, Calvo G, Cruz E, Diego L, et al Libro Blanco de los medicamentos biosimilares en España: Calidad Sostenible. Madrid: Fundación Gaspar Casal; 2014.

4. Revers L, Furczon E. An introduction to biologics and biosimilars. Part II: subsequent entry biosimilars: biosame or biodifferent? Can Pharm J. 2010;143:184-91.

5. Rovira J, Espin J, Garcia L, Olry de Labry A. The impact of biosimilars' entry in the EU market. Sevilla: Andalusian School of Public Health; 2011.

6. López-Púa Y, Ruiz S, Calvo G. Medicamentos biosimilares. Un concepto europeo exportado con éxito a todo el mundo. BioPharmaceuticals. 2013;2:14-19.

7. Schiestl M, Stangler T, Torella C, Cepeljnik T, Toll H, Grau R. Acceptable changes in quality attributes of glycosylated biopharmaceuticals. Nat Biotechnol. 2011;29:310-2.

8. European Medicines Agency. Guideline on Similar Biological Medicinal Products Containing Biotechnology- Derived Proteins as Active Substance: Non-Clinical and Clinical Issues EMEA/CHMP/BMWP/42832/2005. London: EMA; 2006.

9. Weise M, Kurki P, Wolff-HolzE, Bielsky MC, Schneider CK. Biosimilars: the science of extrapolation. Blood. 2014;124:3191-6.

10. Herrero Ambrosio A. Biosimilares: situación regulatoria para su autorización. Farm Hosp. 2010; 34(Supl 1):16-8.

11. Ebbers HC, Muenzberg M, Schellekens H. The safety of switching between therapeutic proteins. Expert Opin Biol Ther. 2012;12:1473-85.
12. Honorato-Pérez J. Evidencia clínica sobre intercambio terapêutico en medicamentos de origen tecnológico. BioPharmaceuticals. 2013; 2:14-19

13. Ebbers HC, Muenzberg M, Schellekens H. The safety of switching between therapeutic proteins. Expert Opin Biol Ther. 2012;12:1473-85.

14. World Health Organization. Expert committee on biological standardization. Geneva, 19 to 23 October 2009. Guidelines on evaluation of similar biotherapeutic products(SBPs). [accessed Jan 2016] Availavle from: http://www.who.int/ biologicals/areas/biological_therapeutics/BIOTHERAPEUTICS FOR WEB 22APRIL2010.pdfhttp://www.who.int/biologicals/areas/biological_therapeutics/BIOTHERAPEUTICS FOR_WEB_22APRIL2010 25. US Food and Drug Administration.

15. Schellekens H. Bioequivalence and the immunogenicity of biopharmaceuticals. Nat Rev Drug Discov. 2002;1:457-62.

16. Schneider CK, Schäffner-Dallmann G. Typical pitfalls in applications for marketing authorization of biotechnological products in Europe. Nat Rev Drug Discov. 2008;7:893-9.

17. Dorantes Calderon B, Montes Escalante IM. Medicamentos biosimilares. Controversias científicas y legales. Farm Hosp. 2010;34 (Supl1):29-44 